\title{
CONTROLE ESTATÍSTICO DO PROCESSO DE COLHEITA SEMIMECANIZADA DE CAFÉ CONILON
}

\author{
STATISTICAL CONTROL OF THE CONILON COFFEE SEMI-MECHANIZED HARVESTING \\ PROCESS
}

\author{
Matheus Nimer Littig ${ }^{1}$ \& Edney Leandro da Vitória ${ }^{2 *}$ \\ ${ }^{123}$ Departamento de Ciências Agrárias e Biológicas, Centro Universitário Norte do Espírito Santo da \\ Universidade Federal do Espírito Santo. ${ }^{1}$ matheusnlittig@gmail.com ${ }^{2 *}$ edney.vitoria@ufes.br
}

\section{ARTIGO INFO.}

Recebido em: 08.05.2021

Aprovado em: 18.05.2021

Disponibilizado em: 24.05.2021

\section{Palavras-chave:}

Mecanização; derriça; recolhimento; coffea canephora.

\section{KEYWORDS:}

Mechanization; strikes; retreat; canephora coffea.

*Autor Correspondente: Vitória, E. L. da

\section{RESUMO}

Comparativamente a outras culturas, a colheita do café conilon é mais difícil de ser executada, em razão do formato da planta, desuniformidade de maturação e do elevado teor de água dos frutos, o que prejudica a mecanização das operações. Dessa forma, o processo de colheita é a etapa final de um processo produtivo, e as perdas devem ser mantidas dentro de padrões aceitáveis. O objetivo do trabalho foi de avaliar qualiquantitativamente o tempo de colheita semimecanizada de café conilon utilizando o controle estatístico do processo (CEP). O estudo ocorreu no município de Pinheiros-ES, onde foram amostrados 30 pontos de recolhimento de um mesmo talhão, selecionados sequencialmente ao início da colheita. Em cada ponto foi avaliada as variáveis tempo de posicionamento da lona, tempo de derriça sobre a lona, tempo de recolhimento da lona, tempo de posicionamento do conjunto trator-recolhedora, tempo total e tempo de manutenção. Ambos os parâmetros analisados apresentaram fora do controle estatístico de processo. Tendo que o tempo de posicionamento da lona apresenta características ou variáveis que influenciam no tempo de distribuição da lona e que o tempo total da colheita semimecanizada não atende aos requisitos do controle estatístico de processo.

\begin{abstract}
Compared to other crops, the conilon coffee harvest is more difficult to execute, due to the shape of the plant, the uneven maturity and the high-water content of the fruits, which impairs the mechanization of the operations. In this way, the harvesting process is the final step of a productive process, and losses must be kept within acceptable standards. The objective of the work was to qualitatively and quantitatively evaluate the time of semi-mechanized harvesting of conilon coffee using statistical process control (CEP). The study took place in the municipality of Pinheiros-ES, where 30 sampling points were sampled from the same plot, selected sequentially at the beginning of the harvest. At each point, the variables times for positioning the tarpaulin, times for stripping over the tarpaulin, time for collecting the tarpaulin, time for positioning the tractor-picker assembly, total time, and maintenance time were evaluated. Both parameters analyzed were out of statistical process control. Bearing in mind that the time for positioning the tarp presents characteristics or variables that influence the time for distributing the tarp and that the total time of the semi-mechanized harvest does not meet the requirements of statistical process control.
\end{abstract}




\section{INTRODUÇÃO}

A cultura do café representa importante fonte de renda e empregos em vários países tropicais, como o Brasil, que é o maior produtor e exportador mundial, sendo o Espírito Santo, o estado com 64\% da produção total de café conilon do país, segundo a Companhia Nacional de Abastecimento (CONAB, 2020).

A cafeicultura brasileira se encontra cada vez mais mecanizada, principalmente nas atividades relacionadas à colheita que, anteriormente, era realizada de forma manual (Silva, 2006). A mecanização nas lavouras cafeeiras iniciou-se com maior vigor na região do Cerrado Brasileiro, principalmente devido aos relevos mais planos (Fernandes, Santinato \& Santinato, 2012) e por ser esta uma técnica que permite redução dos custos operacionais (Silva et al., 2013), podendo reduzir até $60 \%$ dos custos de produção (Santinato et al., 2014). Silva et al. (2013) também observaram que, trabalhando com colheita mecanizada somente na planta e colheita mecanizada na planta e no solo, as reduções de custos foram de 46 e $67 \%$, em relação à colheita manual, respectivamente.

A eficiência da colheita mecanizada do café elevou-se, principalmente, em decorrência da evolução tecnológica das colhedoras, da capacitação dos operadores e do maior conhecimento, por parte dos profissionais que recomendam as regulagens da máquina (Oliveira et al., 2007b). Apesar das melhorias, dificilmente se atingem eficiências próximas a 100\%.

Além das questões relacionadas à eficiência da operação em si, alguns trabalhos têm realizado a análise da qualidade das operações mecanizadas na cafeicultura, visando identificar pontos potenciais e criar um plano de melhorias para eliminar a influência de ações extrínsecas ao processo, aumentando a qualidade das operações (Cassia et al., 2013; Santinato et al., 2014; Silva et al., 2014).

A grande maioria das pesquisas realizadas em relação à colheita de café estão relacionadas ao café arábica, sendo que há poucas pesquisas sobre a colheita semimecanizada do café conilon.

O sistema de colheita semimecanizada usam máquinas recolhedoras/ trilhadoras do café baseadas no sistema de podas anuais e/ou periódicas das lavouras. Estas podas podem ser realizadas de forma drástica ou apenas dos ramos que já produziram frutos em mais de $70 \%$ das gemas. Os ramos provenientes da poda anual dos ramos plagiotrópicos, contendo os frutos, formam leiras que são recolhidos e trilhados mecanicamente ou podem simplesmente alimentar as máquinas de forma manual (Alves et al., 2015).

O controle estatístico de processo (CEP) é uma técnica estatística para o controle da qualidade em operações agrícolas mecanizadas, empregadas em várias culturas, obtendo resultados promissores, uma vez que o controle das operações agrícolas permite a diminuição na variabilidade, obtendo-se resultados mais próximos aos aceitáveis (Compagnon et al., 2012; Silva et al., 2013; Toledo, Silva, \& Furlani, 2013; Voltarelli et al., 2014; Zerbato et al., 2014).

Observações de campo sugerem que existem alguns fatores que interferem no desempenho das recolhedoras, tais como: desníveis e irregularidades do terreno, quantidade de impurezas e quantidade de café. Nesse aspecto, o emprego de ferramentas do controle estatístico de

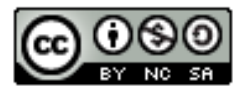

Esta obra está licenciada com uma Licença Creative Commons Atribuição-Não Comercial-Compartilha Igual 4.0 Internacional. Brazilian Journal of Production Engineering, São Mateus, Editora UFES/CEUNES/DETEC. 
qualidade, pode permitir, por meio da análise de cartas de controle, verificar quais e com que intensidade os fatores externos influem na qualidade do recolhimento mecanizado. O objetivo do trabalho foi de avaliar quali-quantitativamente o tempo de colheita semimecanizada de café conilon utilizando o controle estatístico do processo.

\section{Material E Métodos}

O experimento foi conduzido na Fazenda Cremasco, localizada no município de Pinheiros, norte do Espírito Santo, nas coordenadas geográficas de $18^{\circ} 24^{\prime} 27^{\prime \prime}$ Sul, Longitude: $40^{\circ} 13^{\prime} 29^{\prime \prime}$ Oeste, com altitude média de $121 \mathrm{~m}$ e declividade média de $8 \%$. O clima do local é o Aw, de acordo com a classificação de Köeppen, com precipitação média de $1107 \mathrm{~mm}$ anuais, temperatura média de $24^{\circ} \mathrm{C}$ (Alvares et al., 2013). Os ensaios foram conduzidos em uma área de 2,0 ha de lavoura plantada com café conilon, clones 02 e G35, com cinco anos de idade sendo já realizada a poda programada, plantadas no espaçamento de 3,0 m entre linhas e 1,0 m entre plantas, com população média de 3.333 plantas ha-1 $^{-1}$.

Os ensaios referentes às perdas de frutos durante a colheita semimecanizada do café conilon foi realizado na safra 2018, utilizando a recolhedora Double Master 4CR equipada com lona recolhedora.

A recolhedora foi tracionada por um trator 4 x 2 TDA (John Deere 5705N), com potência nominal de 55,2 kW (75 cv) no motor. A marcha de trabalho adotada foi a $2^{\mathrm{a}}$ " $A$ ", trabalhando na rotação nominal de $1700 \mathrm{rpm}$ para possibilitar $540 \mathrm{rpm}$ na TDP e, consequentemente, na máquina. A recolhedora é constituída por uma lona recolhedora, cilindro trilhador, um conjunto de peneiras, turbina e caçamba graneleira. A lona recolhe o material enleirado e, internamente, o submete a um cilindro e a um conjunto de peneiras que separam o café, trituram os resíduos vegetais e eliminam possíveis resíduos minerais; no final das peneiras, a turbina succiona e retira as impurezas mais leves que os grãos de café, armazenando somente o café, em seu compartimento graneleiro de $4 \mathrm{~m}^{3}$. Porém, a separação ainda não é completamente eficiente, de forma que no depósito, juntamente com o café há impurezas minerais e vegetais.

As variáveis analisadas foram: Tempo de posicionamento da lona (TPL): Tempo necessário para o posicionamento da lona sobre a linha de café; Tempo de derriça na lona (TDL): Tempo necessário para que um trabalhador derrice todo o café pendente nos galhos produtivos, sobre a lona de recolhimento.; Tempo de recolhimento da lona (TRL): Tempo necessário para recolher a lona com o café derriçado; Tempo de posicionamento do conjunto trator-recolhedora (TPT): Tempo compreendido entre o final do recolhimento de uma linha e o início de recolhimento da próxima. Este tempo inclui o acoplamento da lona, posicionamento da rampa e engate na recolhedora; Tempo total (TT): Soma dos tempos: TPL, TDL, TRL, TPT; Tempo de manutenção (TM): Tempo perdido com reparos, manutenção e regulagens da máquina.

Foram cronometrados os tempos de 30 linhas de colheita, sendo a lona de 50 metros de comprimento. Os resultados foram inicialmente analisados por meio da estatística descritiva, utilizando-se medidas de tendência central (média aritmética e mediana), medidas de dispersão (amplitude, desvio-padrão e coeficiente de variação), além das medidas de assimetria e de curtose.

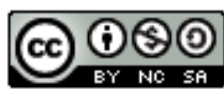


Com relação ao coeficiente de variação de uma distribuição de uma amostra, Pimentel-Gomes e Garcia (2002) os classificam como muito alto (>30\%); alto (entre 21 e 30\%); médio (11 a $20 \%$ ) e baixo (< 10\%) Por outro lado, de acordo com Guimarães (2001), o coeficiente de assimetria (Cs) indica o afastamento da variável, em relação a um valor central. Este índice serve para caracterizar como e quanto à distribuição de frequência se afasta da simetria, sendo que: $\mathrm{Cs}>0$ tem-se uma distribuição assimétrica à direita; se $\mathrm{Cs}<0$ a distribuição é assimétrica à esquerda; e se $\mathrm{Cs}=0$ a distribuição é simétrica. Além disso, se o coeficiente de assimetria for menor que $|0,15|$, a distribuição tem grau de assimetria pequeno; se for maior que $|1,0|$, grau de assimetria elevado e entre $|0,15|$ e $|1,0|$, moderado.

O índice de curtose ( $\mathrm{Ck}$ ) indica a dispersão (achatamento e alongamento) da distribuição em relação a um padrão, geralmente a curva normal. $O$ valor de distribuição simétrica no programa $\mathrm{R}$ é $\mathrm{Ck}=0$ (R Code, 2017). A curtose recebe a seguinte classificação: $\mathrm{Ck}=0$ indica distribuição mesocúrtica, normal; se $\mathrm{Ck}<0$ a distribuição é platicúrtica (achatada) e se $\mathrm{Ck}>0$ a distribuição é leptocúrtica (alongada ou afilada).

Foram confeccionadas cartas de controle para avaliar as perdas durante o sistema de colheita semimecanizada. As cartas de controle utilizadas no estudo das repetições, dentro dos tratamentos, serão medidas individuais para cada tratamento, sendo o tamanho da amostra o número de repetições e medindo-se a variabilidade pela amplitude móvel.

Os limites superior e inferior de controle (LS e LI), bem como a linha central (LC) dos gráficos de emissões médias de CO2, temperatura e umidade do solo, foram calculados, segundo Montgomery (2009), utilizando as seguintes equações:

$$
\begin{aligned}
& L S=\overline{\bar{x}}+A_{2} \cdot \bar{R} \\
& L C=\overline{\bar{x}} \\
& L I=\overline{\bar{x}}-A_{2} \cdot \bar{R}
\end{aligned}
$$

Em que $\overline{\bar{x}}$ é a média das médias amostrais da variável, $A_{2}$ é um valor tabelado (Montgomery, 2009), que varia em função do número de repetições do tratamento e $\bar{R}$ é a média das amplitudes.

Para cada um dos três tipos de perdas serão calculadas as cartas de controle das repetições dos tratamentos e os seus limites inferior e superior e linha central, os gráficos de controle para valores médios de deposição dos tratamentos com seus limites e os gráficos de controle para amplitudes de deposição dos tratamentos com seus limites.

\section{RESULTADOS E DisCUSSÃo}

A Tabela 1 fornece parâmetros da análise descritiva dos dados obtidos do tempo da colheita semimecanizada do café conilon. Os dados indicam que todos os parâmetros analisados exceto o tempo de posicionamento do conjunto trator-recolhedora (TPT) e tempo de manutenção (TM) apresentaram valores médios (11 a 20\%), o TPT apresentou valor alto (entre 21 e $30 \%$ ) e o TM apresentou valor muito alto (>30\%) em relação ao CV (Gomes, 2002), o que não era esperado durante o processo, pois esta manutenção está associada a uma manutenção corretiva, acarretando em um maior tempo gasto para a colheita da mesma. Para amenizar esse problema 
deve-se induzir e realizar manutenções preventivas na máquina para que não haja necessidade de interrupção durante o processo e que resultará em um menor tempo gasto durante a colheita do café.

Tabela 1. Estatística descritiva para as variáveis relacionadas ao tempo de posicionamento da lona (TPL), tempo de derriça na lona (TDL), tempo de recolhimento da lona (TRL), tempo de posicionamento do conjunto trator-recolhedora (TPT), tempo total (TT), tempo de

\begin{tabular}{ccccccc}
\multicolumn{7}{c}{ manutenção $(\mathrm{TM})$} \\
\hline \multirow{2}{*}{ Parâmetros } & $\begin{array}{c}\text { TPL } \\
(\mathbf{m i n})\end{array}$ & $\begin{array}{c}\text { TDL } \\
(\mathbf{m i n})\end{array}$ & $\begin{array}{c}\text { TRL } \\
(\mathbf{s})\end{array}$ & $\begin{array}{c}\text { TPT } \\
(\mathbf{s})\end{array}$ & $\begin{array}{c}\text { TT } \\
(\mathbf{m i n})\end{array}$ & $\begin{array}{c}\text { TM } \\
(\mathbf{m i n})\end{array}$ \\
\hline Média & 10,90 & 6,50 & 92,60 & 23,50 & 19,30 & 2,20 \\
Mediana & 10,20 & 6,60 & 89,80 & 22,90 & 19,00 & 0,00 \\
Amplitude & 7,20 & 3,60 & 78,40 & 16,80 & 7,80 & 21,90 \\
Desvio padrão & 1,80 & 0,90 & 20,50 & 3,40 & 2,10 & 4,90 \\
CV (\%) & 16,20 & 13,58 & 22,15 & 14,35 & 10,92 & 228,30 \\
Cs & 1,10 & $-0,20$ & 1,00 & 0,90 & 0,80 & 3,10 \\
Ck & 0,80 & $-0,40$ & 0,50 & 2,50 & $-0,20$ & 9,80 \\
\hline
\end{tabular}

Os valores para o coeficiente de assimetria $(\mathrm{Cs})$ e coeficiente de curtose $(\mathrm{Ck})$ próxima de zero, exceto para o parâmetro de TM, indica assimetria da distribuição normal. Se analisarmos o TDL, vemos $-0,2$ para Cs e -0,4 para $\mathrm{Ck}$, onde se pode visualizar que a média é menor que a mediana, significa dizer que os tempos estão tendendo a ser menor que a média. Sendo assim, todos os parâmetros que apresentam uma distribuição leptocúrtica, exceto TDL e TT que apresentam uma distribuição platicúrtica.

De acordo com a carta de controle representada pela Figura 1, o parâmetro TPL apresentou-se 90\% fora do controle estatístico de processo, pois ultrapassam os limites inferior e superior de controle indicando a necessidade de melhoria durante o processo de posicionamento da lona. A falta de controle observada durante as repetições podem ser explicadas em função de alguns fatores como: Características físicas de trabalhadores, onde não foram os mesmos indivíduos que realizaram as repetições de posicionamento da lona, tendo como homens e mulheres com suas características distintas que acabam influenciando o resultado final; Idade da planta, como é de característica do café conilon à necessidade de plantio de clones variados na lavoura para que haja a fecundação cruzada entre plantas, com isso clones variados apresentam estruturas arquitetônicas diferentes entre si na qual pode facilitar ou dificultar o trabalho. 
Figura 1. Carta de controle dos tempos de posicionamento da lona (TPL). Média: Média das médias; LI: Limite inferior de controle; LS: Limite superior de controle; LC: Limite central.

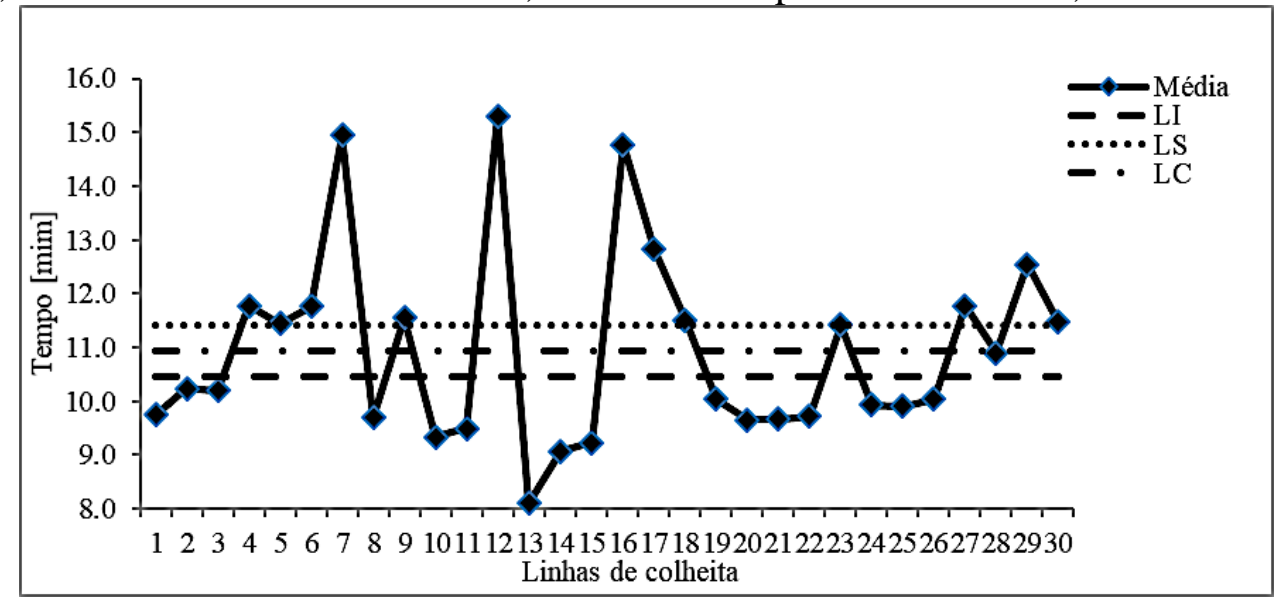

A carta de controle representado pela Figura 2, o parâmetro TDL apresentou-se $80 \%$ fora do CEP por causa da jornada de trabalho, que está associada a pessoas que trabalham de 8 a 10 horas diariamente no período de safra e que sofrem com o cansaço; Características físicas de trabalhadores, disposta por homens e mulheres; Produtividade da planta, por apresentar plantios de clones variados na lavoura conseguintemente haverá clones com estruturas arquitetônicas diferentes e com produtividade variada ocasionando gasto de tempo distinto durante a derriça. A colheita semimecanizada utilizando este processo de lona de recolhimento é utilizado exclusivamente para o café conilon. Entretanto, a influência de alguns parâmetros, tais como características físicas do trabalhador braçal, idade da planta e limpeza das entrelinhas também foi observado em trabalhos de colheita manual ou mecanizado na colheita do café arábica (Santinato, et al., 2014). Oliveira et al. (2007) avaliando os custos operacionais da colheita mecanizada do café arábica verificaram que quando se colheram manualmente, gastaram aproximadamente 376 horas $\mathrm{ha}^{-1}$ e quando se utilizou uma colhedora mecanizada o tempo foi reduzido de 3,14 horas ha-1 a uma velocidade de $0,72 \mathrm{~m}^{\mathrm{s}-1}$, tendo como a redução de custo chegando até $62,36 \%$ em relação a colheita manual.

Figura 2. Carta de controle dos tempos de derriça na lona (TDL). Médias: Média das médias; LI: Limite inferior de controle; LS: Limite superior de controle; LC: Limite central.

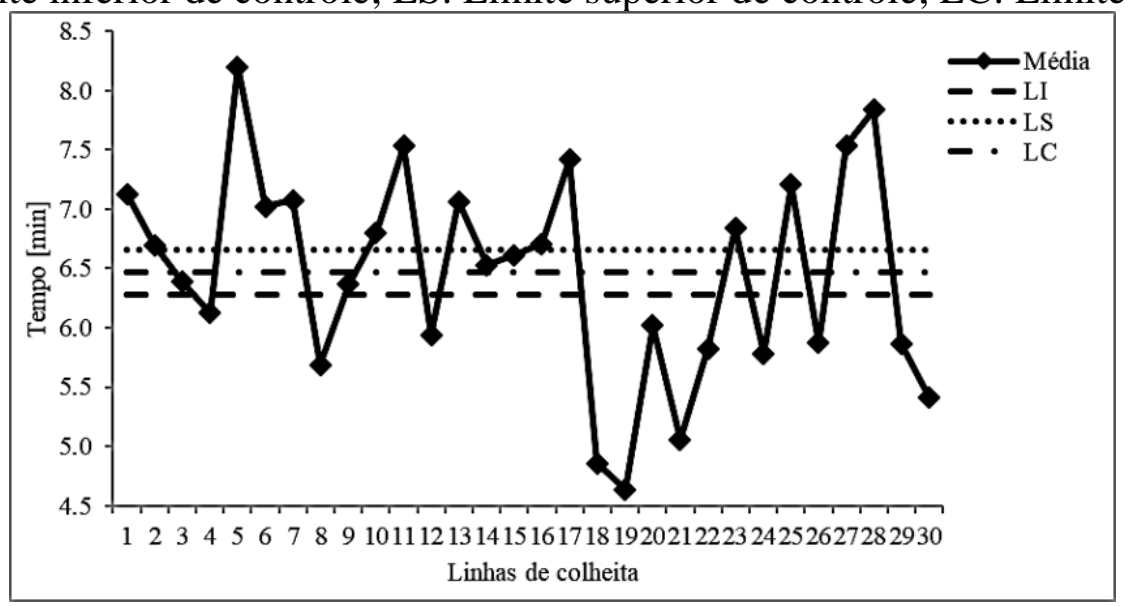

A carta de controle representado pela figura 3 demonstra o parâmetro TRL que apresentou 93,3\% fora do CEP em função da umidade em que se apresentava o café já derriçado na lona 
dificultando sua separação e/ou embuchamento, gerando atraso no processo, visto que o café derriçado na lona só será processado pela recolhedora no dia seguinte.

Figura 3. Carta de controle dos tempos de recolhimento da lona (TRL). Médias: Média das médias; LI: Limite inferior de controle; LS: Limite superior de controle; LC: Limite central.

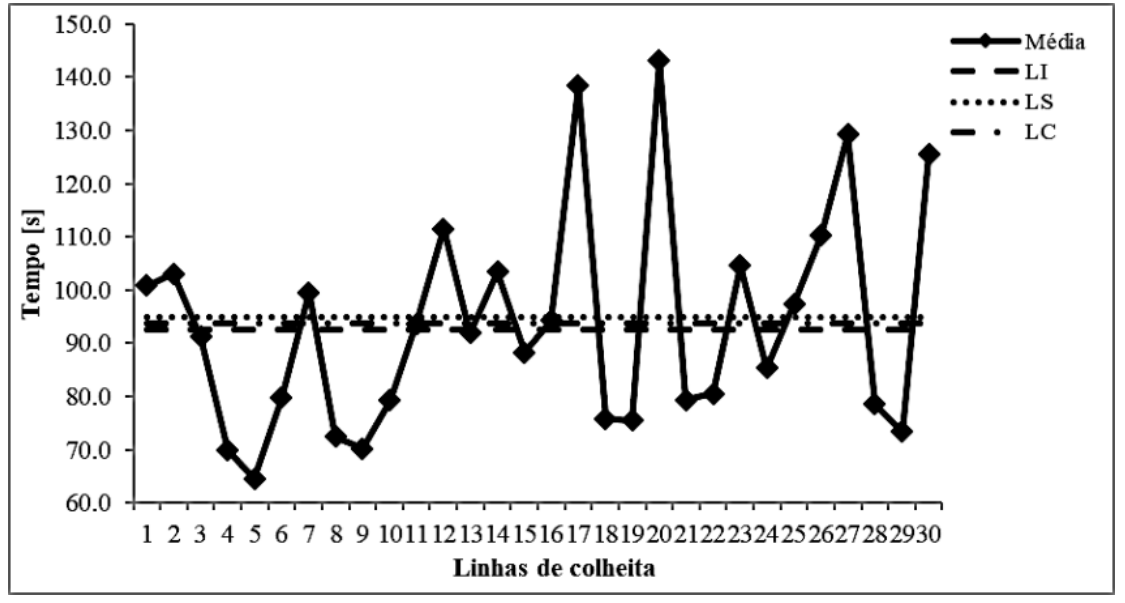

Silva et al. (2014) observaram a influência do teor de água em plantas de feijão arrancadas e expostas no solo antes do recolhimento da máquina influenciam na eficiência do recolhimento e separação do grão da vagem devido ao acúmulo de material no sistema de recolhimento.

Com relação à carta de controle representado pela Figura 4, o parâmetro TPT apresentou-se 73,3\% fora do CEP pelo alinhamento da recolhedora para com a linha de plantio na qual será acoplada a lona para o recolhimento da mesma.

Figura 4. Carta de controle dos tempos de posicionamento do conjunto trator-recolhedora (TPT). Médias: Média das médias; LI: Limite inferior de controle; LS: Limite superior de controle; LC: Limite central.

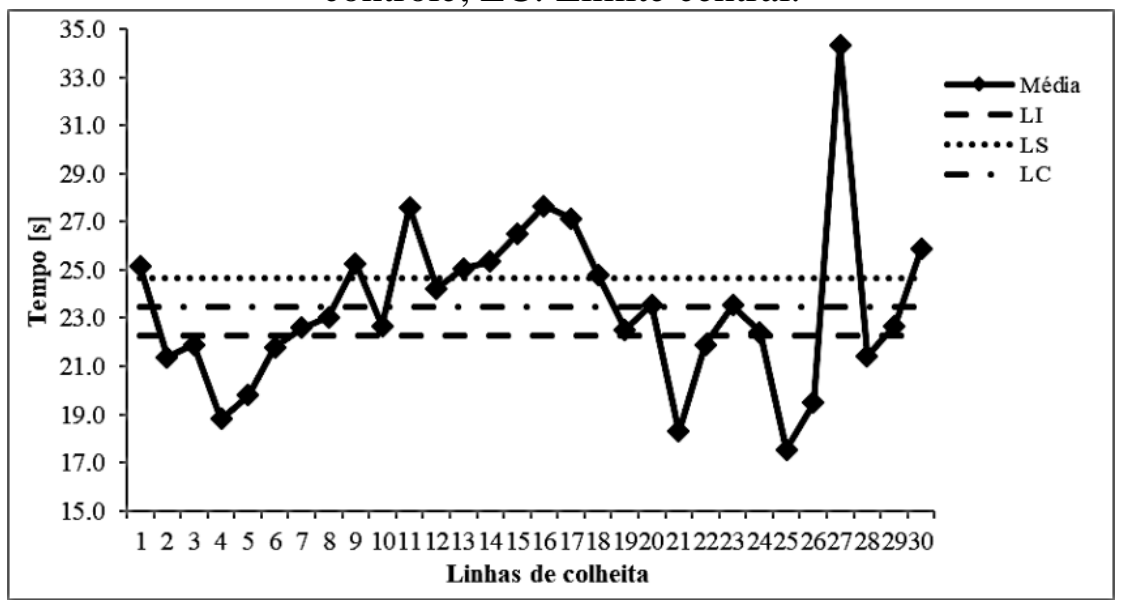

Com relação à carta de controle representado pela Figura 5, o parâmetro TT é totalmente influenciado pelos demais tempos apresentados anteriormente, onde irá influenciar o tempo total de recolhimento e na capacidade operacional de todo o processo de recolhimento semimecanizado, apresentando $76,7 \%$ de seu processo fora do CEP. 
Figura 5. Carta de controle dos tempos totais (TT). Médias: Média das médias; LI: Limite inferior de controle; LS: Limite superior de controle; LC: Limite central.

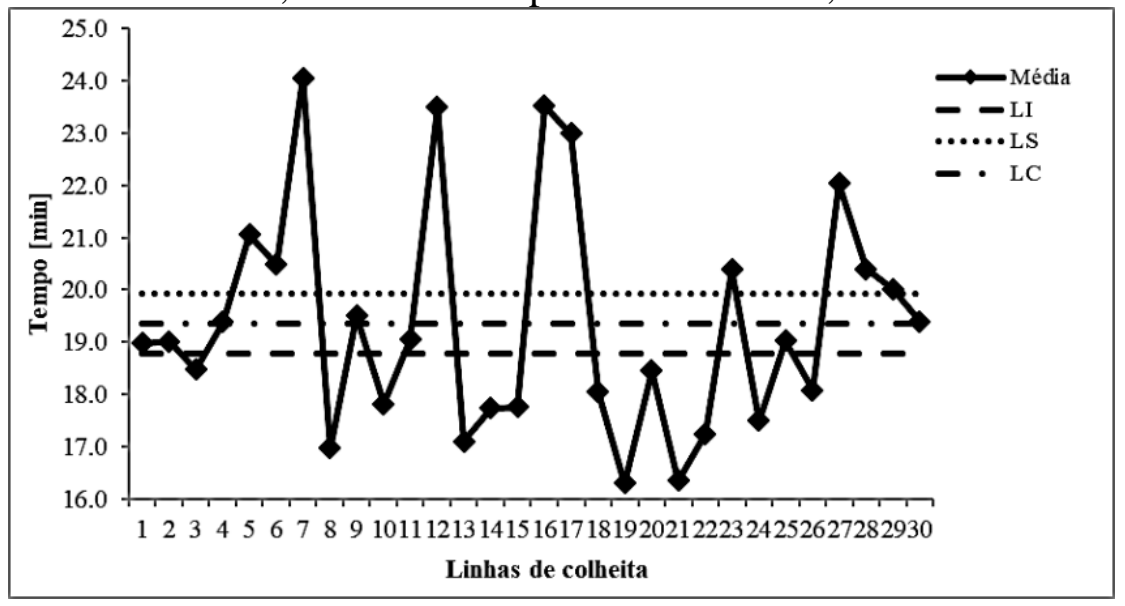

A carta de controle representado pela Figura 6 demonstra o parâmetro TM que não era esperado no processo, visto que é uma manutenção corretiva. Como o TM foi um processo atípico em função de uma manutenção corretiva é natural que esteja fora do CEP.

Figura 6. Carta de controle dos tempos de manutenções (TM), onde está sendo apresentado o gráfico de controle para valores médios. Médias: Média das médias; LI: Limite inferior de controle; LS: Limite superior de controle; LC: Limite central.

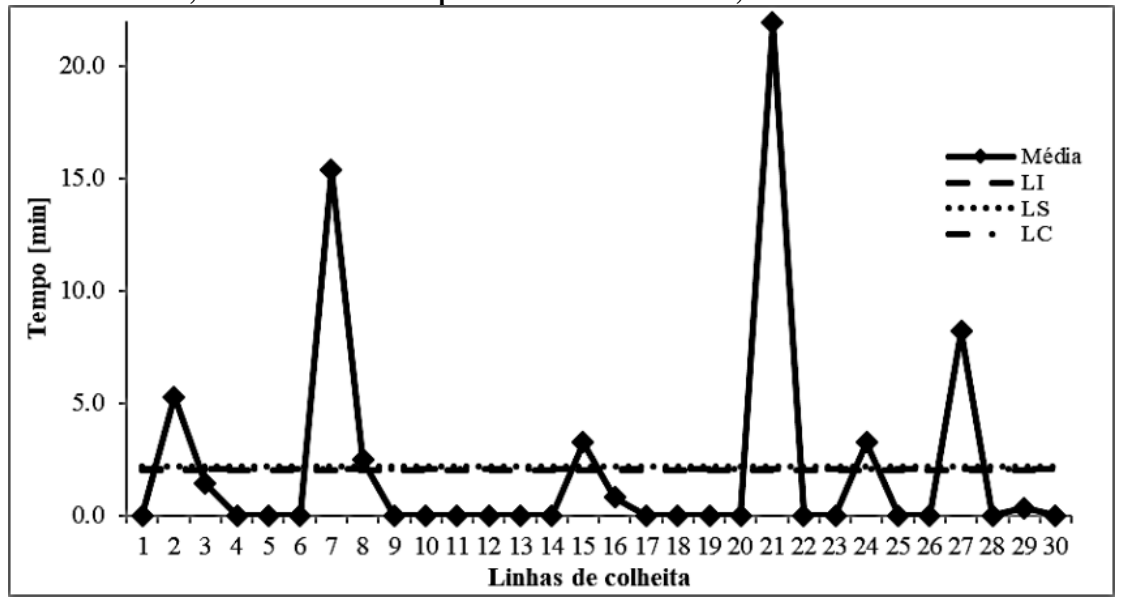

O tempo de parada e manutenção da máquina recolhedora é um ponto que influenciou no tempo total de colheita, nas linhas de recolhimento 2, 7, 1521 e 24 e 27 foram em médias 150\% superior ao tempo médio. Toledo et al. (2013) e Santinato et al. (2013) indicaram que o planejamento adequado em relação aos condições de manutenção e paradas programadas das máquinas de recolhimento e colheita podem aumentar a eficiência de campo em $20 \%$.

Dias et al. (2013) avaliando a colheita mecanizada de café por meio do CEP verificaram que as cartas de controle são um método eficiente na avaliação da qualidade e identificação dos pontos fora de controle dos processo de colheita mecanizada de café.

\section{Conclusões}

- O controle estatístico de processo é uma ferramenta importante no controle da eficiência das operações de colheita semimecanizada do café conilon 
- O tempo de posicionamento de lona apresenta características ou variáveis que influenciam no tempo.

- O tempo total da colheita semimecanizada não atende aos requisitos do controle estatístico de processos.

- O tempo de manutenção do conjunto trator-recolhedora tem influência no tempo total.

\section{Referências Bibliográficas}

Alvares, C.A., Stape, J.L., Sentelhas, P.C., Gonçalves, J.L.M., \& Sparovek, G (2013). Köppen's climate classification map for Brazil. Meteorologische Zeitschrift, 22(6), 711-728. http://dx.doi.org/10.1127/0941-2948/2013/0507

Alves, E. A., Costa, J. N. M., \& Santos, J. C. F (2015). Procedimentos de colheita de café. In: Marcolan, A. L., Espindula, M. C. (Ed.). Café na Amazônia. Brasília: Embrapa. p. 345 - 358. https://www.embrapa.br/busca-de-publicacoes/-/publicacao/1023755/cafe-na-amazonia

Cassia, M. T., Silva, R. P. D., Chioderolli, C. A., Noronha, R. H. F., \& Santos, E. P. D (2013). Quality of mechanized coffee harvesting in circular planting system. Ciência Rural, 43(1), 2834. https://doi.org/10.1590/S0103-84782012005000148

Compagnon, A. M., Silva, R. P., Cassia, M. T., Graat, D., \& Voltarelli, M. A. (2012). Comparação entre métodos de perdas na colheita mecanizada de soja. Scientia agropecuária, 3(3), 215-223. doi.org/10.17268/sci.agropecu.2012.03.03

CONAB. Acompanhamento Da Safra Brasileira De Café| v.6 - Safra, n.3 - terceiro levantamento, setembro de 2020. Recuperado de https://www.conab.gov.br/infoagro/safras/cafe

Davis, A. P., Govaerts, R., Bridson, D. M., \& Stoffelen, P. An annotated taxonomic conspectus of the genus Coffea (Rubiaceae) (2006). Botanical Journal of the Linnean Society, 152(4), 465512. https://doi.org/10.1111/j.1095-8339.2006.00584.x

Dias, R. E. B. A., Silva, F. M. D., Cunha, J. P. B., Avelar, R. C., Fernandes, F. C., Santos, M. C., \& Figueiredo, V. C. (2013). Avaliação da colheita mecanizada de café por meio do Controle Estatístico de Processos (CEP). VIII Simpósio de Pesquisa dos Cafés do Brasil, 25 a 28 de Novembro de 2013, Salvador.

Fernandes, A. L., Santinato, F., \& Santinato, R. (2012). Utilização da subsolagem na redução da compactação do solo para produção de café cultivado no cerrado mineiro. Enciclopédia Biosfera, 8(15), 1648-1656. https://conhecer.org.br/ojs/index.php/biosfera/article/view/3732

Montgomery, D. C. Introdução ao controle estatístico da qualidade. Tradução Ana Maria Lima de Farias, Vera Regina Lima de Farias e Flores. Revisão técnica Luiz da Costa Laurencel. 4. ed. Rio de Janeiro: LTC, 2009.

Oliveira, E. D., Silva, F. M. D., Salvador, N., Souza, Z. M. D., Chalfoun, S. M., \& Figueiredo, C. A. P. D. (2007). Custos operacionais da colheita mecanizada do cafeeiro. Pesquisa Agropecuária Brasileira, 42(6), 827-831. https://doi.org/10.1590/S0100-204X2007000600009

Oliveira, E. D., Silva, F. M. D., Salvador, N., \& Figueiredo, C. A. (2007). Influência da vibração das hastes e da velocidade de deslocamento da colhedora no processo de colheita mecanizada do café. Engenharia Agrícola, 27(3), 714-721. https://doi.org/10.1590/S010069162007000400014 
Gomes, F. P., \& Garcia, C. H. (2002). Estatística aplicada a experimentos agronômicos e florestais. Piracicaba: Fealq, 11, 21.

Santinato, F., Silva, R. P. D., Cassia, M. T., \& Santinato, R. (2014). Análise quali-quantitativa da operação de colheita mecanizada de café em duas safras. Coffee Science, 9(4), 495-505. http://www.sbicafe.ufv.br/handle/123456789/8091

Santinato, F., Silva, R. P., Ruas, R. A. A., Cassia, M. T., \& Santinato, R (2013). Comparação entre o custo da colheita manual e mecanizada de uma a seis passadas da colhedora. In: Congresso Brasileiro De Pesquisas Cafeeiras, 39., 2013, Poços de Caldas. Resumos Expandidos... Poços de Caldas: MAPA/PROCAFÉ, p. 195-198. Link: Congresso Brasileiro De Pesquisas Cafeeiras

Silva, F. M. D., Souza, Z. M. D., Arré, T. J., Juan, R. S., \& Oliveira, E. D. (2006). Avaliação da colheita mecanizada do café com uso de ethephon. Coffee Science, 1(1), 1-6. http://www.sbicafe.ufv.br/handle/123456789/3910

Silva, R. P. D., Cassia, M. T., Voltarelli, M. A., Compagnon, A. M., \& FURLANI, C. E. A. (2013). Qualidade da colheita mecanizada de feijão (Phaseolus vulgaris) em dois sistemas de preparo do solo. Revista Ciência Agronômica, 44(1), 61-69. https://doi.org/10.1590/S180666902013000100008

Silva, R. P. D., Voltarelli, M. A., Cassia, M. T., Vidal, D. O., \& Cavichioli, F. A. (2014). Qualidade das operações de preparo reduzido do solo e transplantio mecanizado de mudas de café. Coffee Science, 9(1), 51-60. http://www.sbicafe.ufv.br/handle/123456789/8015

Toledo, A., Silva, R. P., \& Furlani, C. E. A (2013). Quality of cut and basecutter blade configuration for the mechanized harvest of green sugarcane. Scientia Agricola, 70(6), 384389. https://doi.org/10.1590/S0103-90162013000600002 